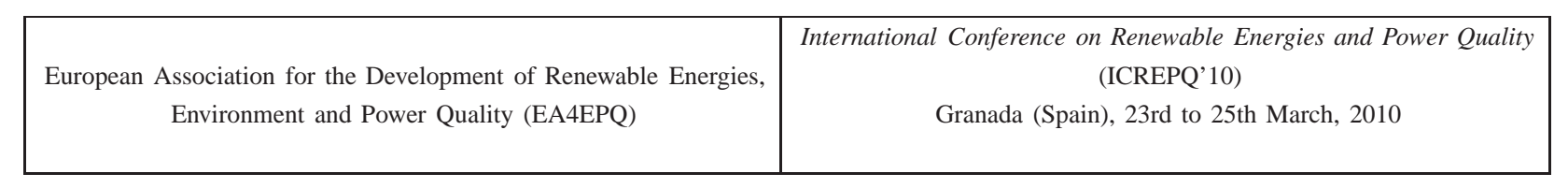

\title{
The role of the dc-bus in voltage sags experienced by three-phase adjustable-speed drives
}

\author{
Mañana, M.; Muñiz, L.M.; Ortiz, A.; Aranda, R.; Arroyo, A.; Delgado, F. \\ Department of Electrical Engineering \\ E.T.S.I.I.T. University of Cantabria \\ Avda. Los Castros s/n \\ 39005 Santander, Cantabria \\ Spain \\ Phone: +34942201378 Fax: +34942201385 Email: mananam@unican.es
}

\begin{abstract}
This research work is devoted to the critical evaluation of the role of the dc-bus in the behavior of threephase adjustable-speed drives with voltage sags. In particular, the dc-link voltage variation under voltage sag and its dependence on bus capacity, dc-link resistance and inductance and source impedance.

The analysis can be used to introduce additional capacitance in the dc-link in order to increase the ride-through capability of the ASD.

Both an electromagnetic transient model and a set-up facility have been introduced. This test platform can be used in order to study the sensitivity of ASD to different disturbances.
\end{abstract}

Keywords. power quality, sags, PWM drives, ASD

\section{Introduction}

A voltage sag or dip can be defined as a reduction of the voltage related to the nominal value with a duration that can go from one cycle to some few seconds. It is well known that voltage sags are produced by short circuits, motor starting, maniobres in breakers, electrical welding machines and other loads with sudden and intermittent power demand. The effects of voltage sags on adjustablespeed drives (ASD) has been studied from different points of view [1-10]. In Bollen [3] it is possible to find conclusions about the economic cost of sags in several types of industrial applications. Duran-Gomez et all. [11] proposes a critical evaluation of the effect of voltage sags on ASD's, underlying the dc-link voltage variation under voltage sags and its dependence on source impedance, dclink inductance and output load. In a complementary way Collins et all. [5] reviews the behavior of ac motor drives during sags. Zyl et all. [12] introduces a methodology for incorporating voltage sag ride-through in the design of ASD's with active rectifiers. https://doi.org/10.24084/repqj08.575

\section{Electric Circuit Model}

The simplified equivalent electric circuit model of the ASD is shown in fig. 2. The average value of the dclink under steady state operating conditions is given by Mohan et all. [13],

$$
V_{d c, i}=\frac{3 \sqrt{2}}{\pi} V_{L L}
$$

where,

$V_{d c, i}$ Steady-state mean value at the output of the rectifier converter.

$V_{L L} \quad$ rms value of the line-to-line voltage of the utility input supply.

In order to reduce the complexity of the study, only balanced three-phase sags are considered. Fig. 1 shows a typical case A [3] sag. A simple sag can be characterized using the residual voltage $V_{d c, r}$ and the duration $t_{s a g}$.

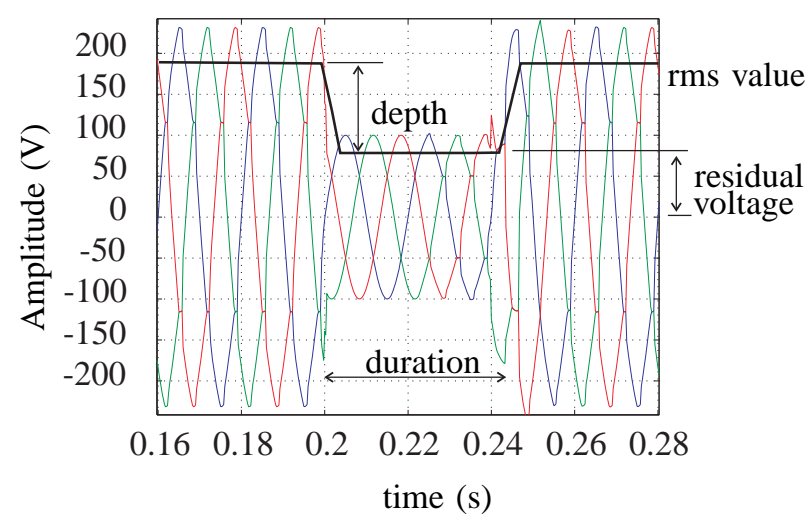

Figure 1. Typical parameters of a voltage sag.

The instantaneous dc-bus voltage at output $v_{d c, o}$ is computed by the instantaneous current $i_{C}$ through the link capacitor $C$,

RE\&PQJ, Vol.1, No.8, April 2010 


$$
C \frac{d v_{d c, o}(t)}{d t}=i_{C}(t)=i_{d c, i}(t)-i_{d c, o}(t)
$$

Cano et all [4] propose an equation that can be used to compute the time needed $\left(t_{\max }\right)$ to discharge the capacity $C$ at dc-bus

$$
t_{\max }=\frac{C\left(V_{d c, o}^{2}-V_{d c, t}^{2}\right)}{2 P}
$$

where,

$t_{\max }$ Maximum time before the undervoltage protection at ASD trips.

$C$ dc-bus capacity.

$V_{d c, o}$ rms dc-bus voltage at inverter input.

$V_{d c, t}$ rms dc-bus voltage that produces an undervoltage trip at ASD.

$P \quad$ Active power demanded by the ASD.

Fig. 3 shows the computed value of $t_{\max }$ as a function of $C / P$ and $V_{d c, t}$.

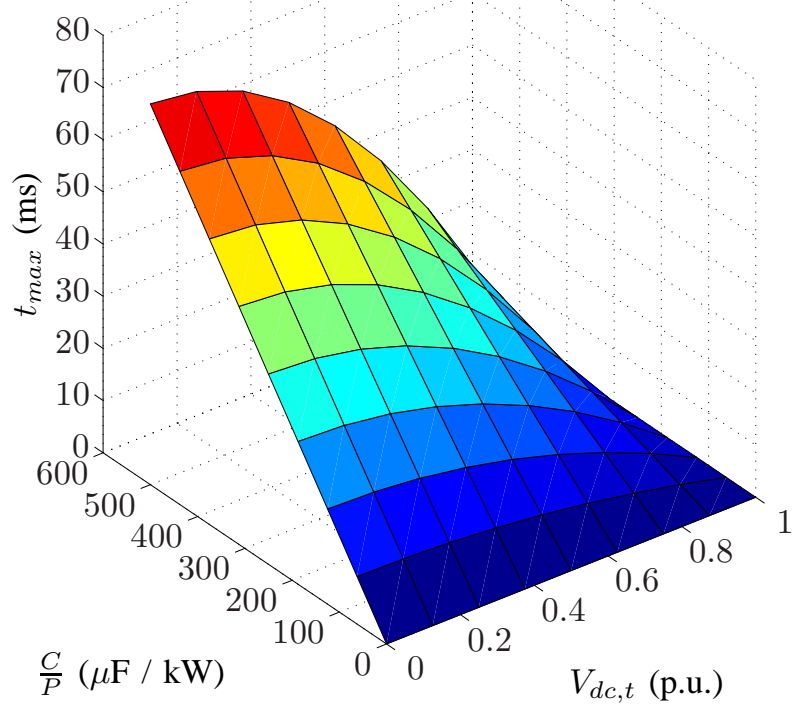

Figure 3. Maximum voltage sag duration for and ASD as a function of $V_{d c, t}$ and the ratio $C / P$.

The basic model of Fig. 2 has been implemented using PSCAD [14]. This model can be considered a basic approach for analyzing the behavior of the residual voltage at dc-bus as a function of $L_{d c}, C, R_{g}, L_{g}$ and the voltage sag depth and duration.

\section{Set-up facility}

A Set-up facility suitable for testing the behavior of the ASD to voltage sags has been developed. The facility has a programmable power supply with the ability to generate three-phase arbitrary waveforms. Fig. 4 summarizes the structure of the proposed test system. The facility also includes a programmable mechanical load that can be used to simulate typical loads.

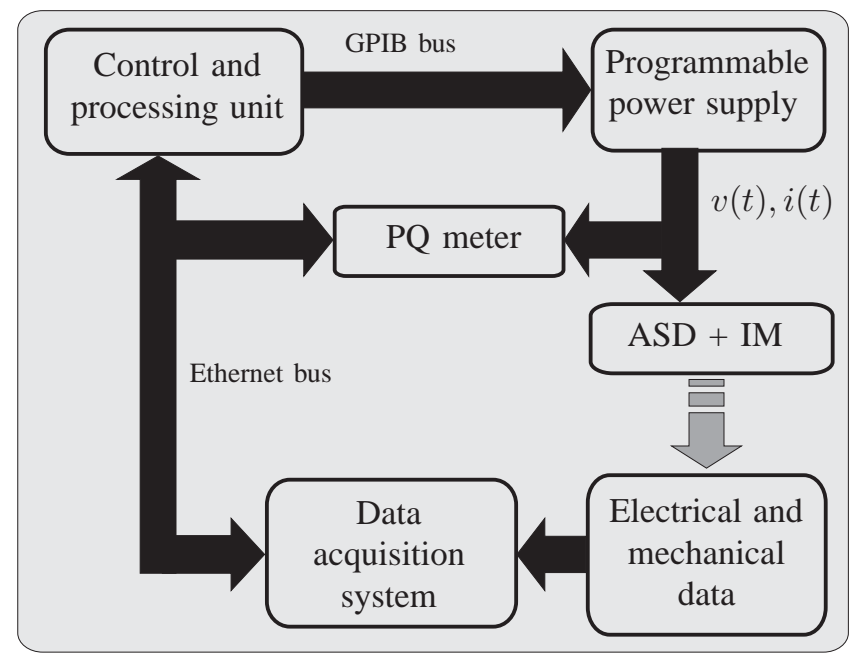

Figure 4. Set-up facility for sags testing.

\section{Results}

The basic equivalent circuit of fig. 2 has been simulated using PSCAD/EMTDC [14] for a $1.5 \mathrm{~kW}$ equivalent machine. The model is shown in Fig. 7. This software has a powerful multiple run module that can be used to study the sensitivity of electrical parameters.

Among other factors, the ratio between the power of the driver and the short-circuit power at common coupling point will define the effects of voltage dips on the dc-link. Fig. 5 shows the impact of voltage dips over the dc-bus as a function of the ratio between the short-circuit power and the nominal power of the ASD considering a dc-link capacity $C$ of $300 \mu F$.

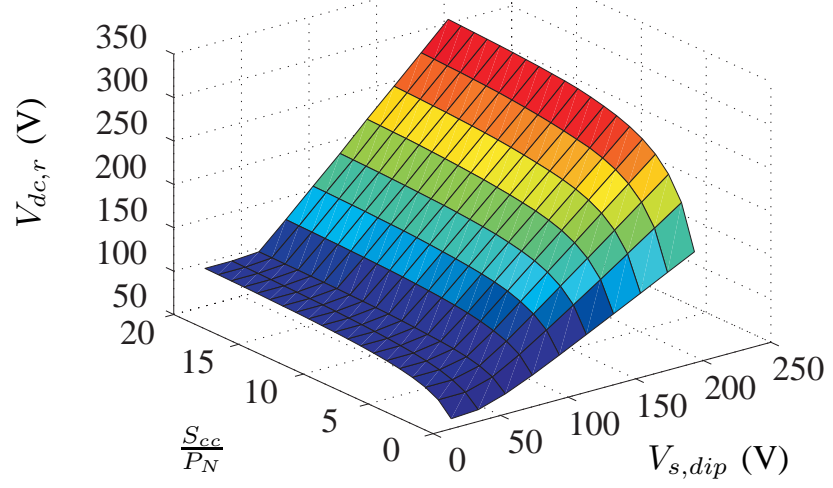

Figure 5. Residual voltage at dc-bus during a sag as a function of the $\frac{S_{c c}}{P_{N}}$ ratio and the residual voltage at source.

Fig. 5 shows that, from a general point of view, the residual value of the voltage sag is almost similar to the residual value of the voltage supply when the ratio between the short-circuit power at common coupling point and the nominal power of the driver is greater or equal to 15 .

Fig. 6 shows that dc-bus capacity $C$ plays the most important role in the behavior of the overall system regarding voltage dips. 
\begin{tabular}{l|l|l|l|l}
$\begin{array}{c}\text { Power supply } \\
\text { network }\end{array}$ & Rectifier & de bus & Inverter
\end{tabular}

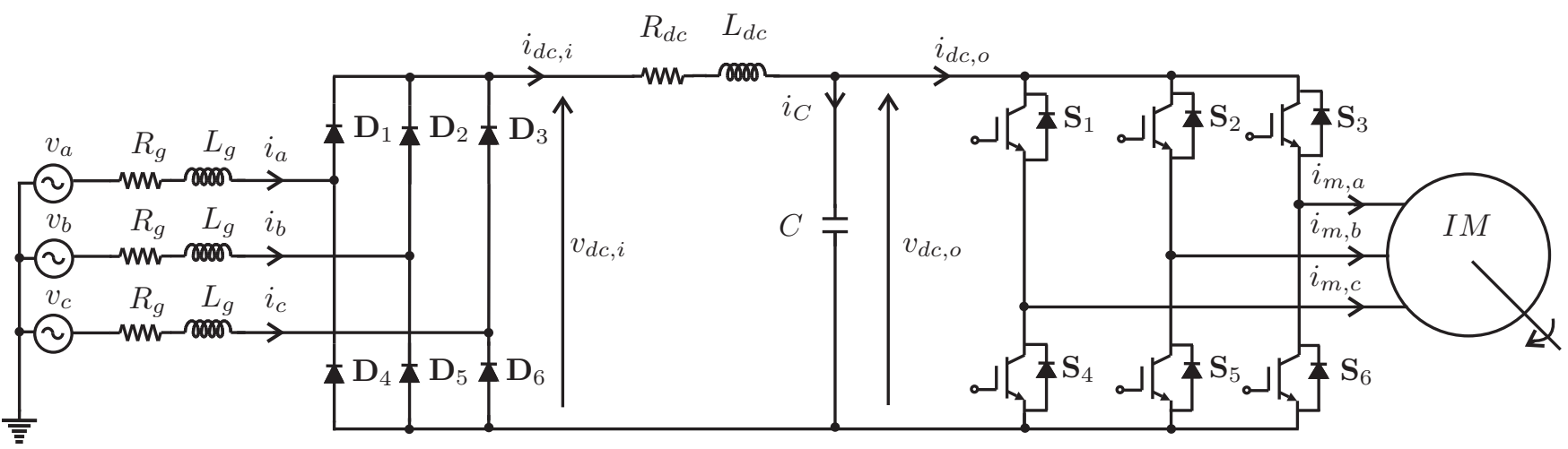

Figure 2. Equivalent circuit model of the ASD power stage.

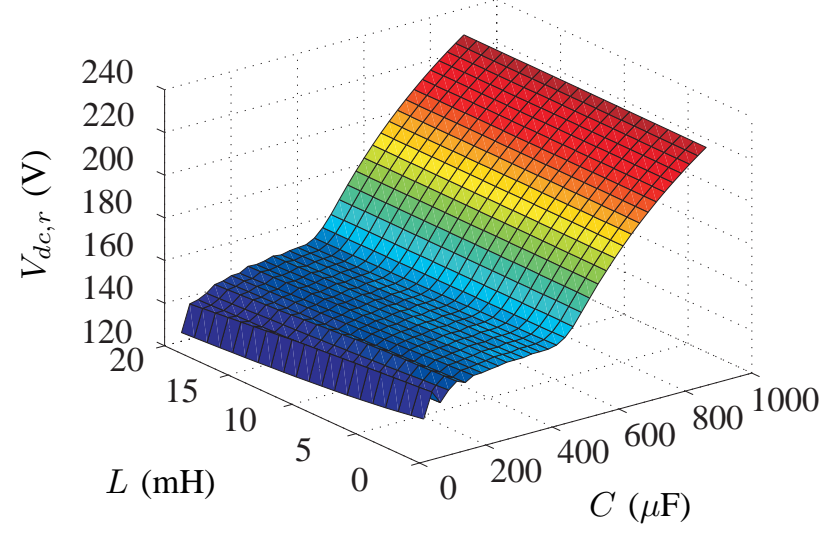

Figure 6. Residual voltage at dc-bus during a sag as a function of the dc-link $C$ and $L_{d c}$

\section{Conclusions}

The survival of the ASD to voltage sags depends on the trip-point settings of the drive protections and the way the control is implemented. Undervoltage protection with a trip point set close to the nominal voltage will cause high sensitivity to sags. An increase in the capacity at dc-bus will increase their immunity to voltage sags.

\section{Acknowledgment}

The authors would like to thank the support of the Spanish Government under the research project ENE2007-68032-C04-04/CON.

\section{Appendix PSCAD/EMTDC Basic Model}

Fig. 7 shows the PSCAD basic model used for sensitivity analysis. It is important to underline the multirun component. This module can be used to control a multiple run simulation. Up to six variables can be controlled and the component can record up to six channels each run. https://doi.org/10.24084/repqj08.575

\section{References}

[1] M. T. Aung and J. Milanovic, "Analytical assessment of the effects of voltage sags on induction motor dynamic responses," in Power Tech, 2005 IEEE Russia, June 2005, pp. 1-7.

[2] M. Bollen, "Characterisation of voltage sags experienced by threephase adjustable-speed drives," Power Delivery, IEEE Transactions on, vol. 12, no. 4, pp. 1666-1671, Oct 1997.

[3] M. H. J. Bollen, Voltage Sags and Interruptions. John Wiley \& Sons, 2000.

[4] J. Cano, G. Orcajo, C. Rojas, M. Melero, and M. Cabanas, "Technical and economical assessment of the effect of voltage sags on adjustable speed drives," in International Conference on Renewable Energies and Power Quality (ICREPQ), Barcelona, 2004

[5] J. Collins, E.R. and A. Mansoor, "Effects of voltage sags on ac motor drives," in Textile, Fiber, and Film Industry Technical Conference, 1997., IEEE 1997 Annual, May 1997.

[6] J. Gomez and M. Morcos, "Specific energy concept applied to the voltage sag ride-through capability of sensitive equipment in dg embedded systems," Power Delivery, IEEE Transactions on, vol. 18 , no. 4, pp. 1590-1591, Oct. 2003.

[7] R. Langley, A. Mansoor, J. Collins, E.R., and R. Morgan, "Voltage sag ride-through testing of adjustable speed drives using a controllable dynamic dynamometer," in Harmonics And Quality of Power, 1998. Proceedings. 8th International Conference on, vol. 1, Oct 1998, pp. 566-571 vol.1.

[8] J. Milanovic, S. Vegunta, and M. Aung, "The influence of induction motors on voltage sag propagationpart ii: Accounting for the change in sag performance at lv buses," Power Delivery, IEEE Transactions on, vol. 23, no. 2, pp. 1072-1078, April 2008.

[9] H. Ndjana, P. Sicard, S. Lahaie, and E. Ngandui, "Auxiliary voltage sag ride-through system for adjustable-speed drives," in Electric Machines and Drives, 2005 IEEE International Conference on, May 2005, pp. 450-457.

[10] G. Orcajo, J. Cano, C. Rojas, M. Melero, M. Cabanas, and F. Pedrayes, "Voltage sags in industrial systems," in International Conference on Renewable Energy and Power Quality (ICREPQ), Zaragoza, 2005.

[11] J. Duran-Gomez, P. Enjeti, and B. O. Woo, "Effect of voltage sags on adjustable-speed drives: a critical evaluation and an approach to improve performance," Industry Applications, IEEE Transactions on, vol. 35, no. 6, pp. 1440-1449, Nov/Dec 1999.

[12] A. Van Zyl, R. Spee, A. Faveluke, and S. Bhowmik, "Voltage sag ride-through for adjustable-speed drives with active rectifiers," Industry Applications, IEEE Transactions on, vol. 34, no. 6, pp. 1270-1277, Nov/Dec 1998.

[13] N. Mohan, T. Undeland, and W. Robbins, Power Electronics: Converters, Applications and Design, 2nd ed. Wiley, 1995.

[14] PSCAD Electromagnetic Transient. User's Guide. V4.2. 

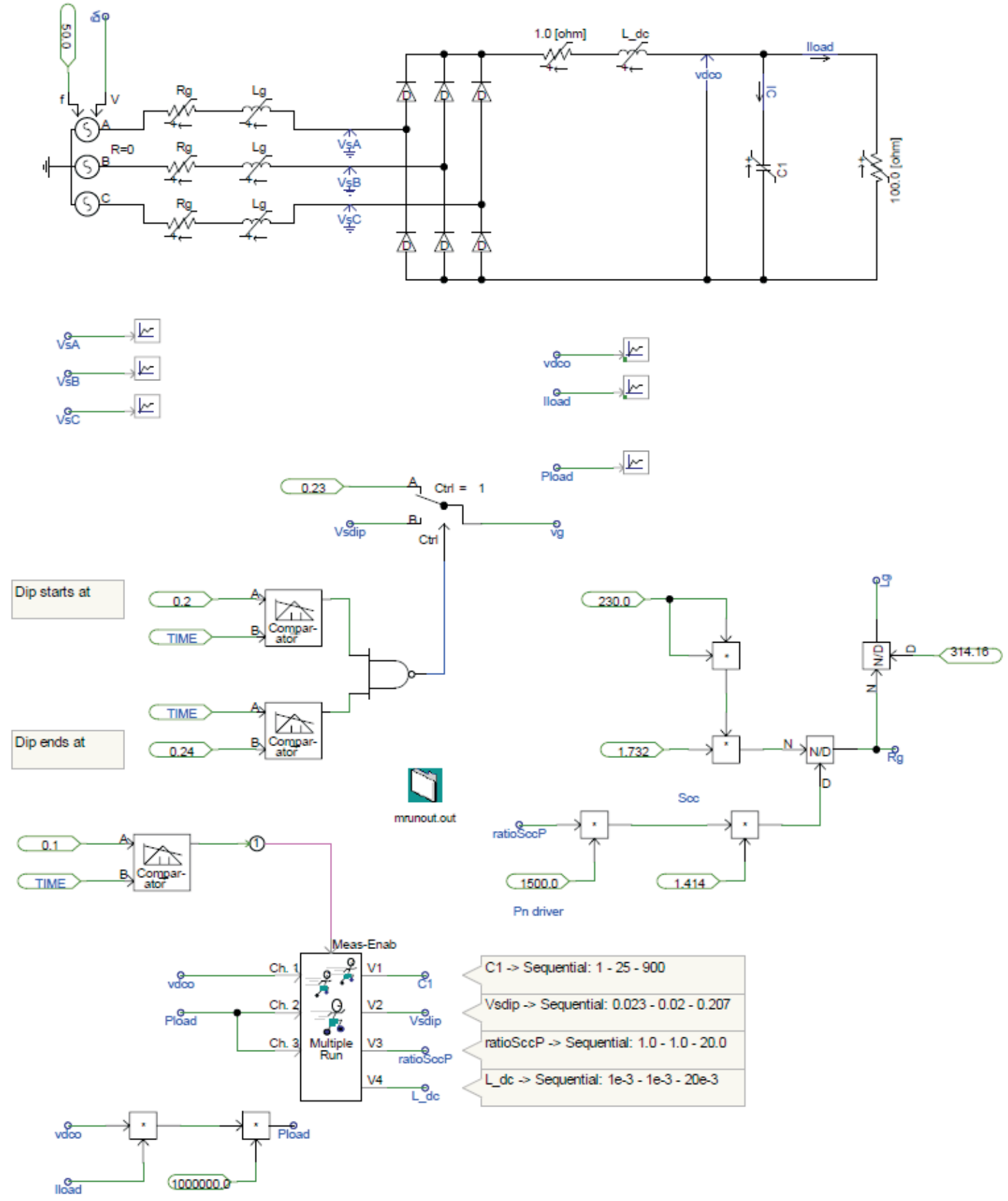

Figure 7. Basic PSCAD model used for sensitivity analysis. 